\title{
Immunosuppressants: Implications in Orthodontics
}

Rogério Lacerda dos Santos', Maria Cláudia Mesquita Lacerda², Renato Torres Gonçalves³, Marco Aurélio Martins ${ }^{4}$, Margareth Maria Gomes de Souza ${ }^{5}$

Introduction: There are medications capable of affecting bone metabolism and the rate of tooth movement. Among these medications are the immunosuppressants, which act by repressing the action of Tymphocytes, however they can cause bone loss and consequently lead to osteoporosis. Osteoporosis is a common complication following kidney, heart, liver or lung transplantation. The immunosuppressant treatment for preventing organ rejection after transplantation, in general, includes glucocorticoids, cyclosporine, tacrolimus, and sirolimus. All these drugs can have jeopardizing effects on bone mineral homeostasis and consequently influence tooth movement. In recent years, however, the increasing use of immunosuppressants has raised questions about their effects on bone metabolism in patients undergoing orthodontic treatment.

Objective: The objective of this review study was to inform orthodontists about the influence of immunosuppressants on bone metabolism and tooth movement.

Keywords: Immunosuppressant. Tooth movement. Bone.

${ }^{1}$ Specialist in Orthodontics, Federal University of Alfenas. MSc and PhD in Orthodontics, Federal University of Rio de Janeiro. Adjunct Professor of Orthodontics, Federal University of Campina Grande.

${ }^{2}$ Specialist in Linguistics, State University of Minas Gerais.

${ }^{3}$ Nephrologist, Department of Nephrology and responsible for the Renal Transplantation Unit of the Clementino Fraga Filho University Hospital (HUCFF), Rio de Janeiro, Brazil

${ }^{4} \mathrm{PhD}$ in Cell and Molecular Biology, Fiocruz, Rio de Janeiro. Chief of the Inflammation Laboratory of Fiocruz, Rio de Janeiro, Brazil.

${ }^{5} \mathrm{MSc}$ and $\mathrm{PhD}$ in Orthodontics, Federal University of Rio de Janeiro. Associate Professor of Orthodontics, Federal University of Rio de Janeiro.
How to cite this article: Santos RL, Lacerda MCM, Gonçalves RT, Martins MA Souza MMG. Immunosuppressants: Implications in Orthodontics. Dental Press J Orthod. 2012 Mar-Apr;17(2):55-61.

Submitted: July 25, 2008 - Revised and accepted: January 26, 2009

» The authors report no commercial, proprietary, or financial interest in the products or companies described in this article.

Contact address: Rogério Lacerda dos Santos Universidade Federal de Campina Grande - UFCG

Centro de Saúde e Tecnologia Rural - CSTR. Av. dos Universitários, S/N, Rodovia Patos/Teixeira, Km 1, Santa Cecília - CEP: 58700-970 - Patos/PB - Brazil.

E-mail: lacerdaorto@hotmail.com - orlacerdaorto@bol.com.br 


\section{INTRODUCTION}

There are medications capable of affecting bone metabolism and the rate of tooth movement. ${ }^{11}$ Some of these medications are the immunosuppressants inhibitors of calcineurin-phosphatase (cyclosporin and tacrolimus), which are partly responsible for greater survival of transplanted patients and for the reduction in the glucocorticoids doses. However, similarly to the glucocorticoids, calcineurin-phosphatase inhibitors also cause reduction in bone mass, with the greatest bone loss occurring in the first 6 months after transplantation, when immunosuppressant therapy is most aggressive ${ }^{9}$. Even though the present tendency is to use a lower total dose of immunosuppressants, many transplanted patients continue to develop fractures as a complication. ${ }^{7}$ Immunosuppressant drugs may be grouped into biologic and chemical categories, according to the location of their action and their effects on lymphocytes. ${ }^{1}$ The most frequently used immunosuppressants nowadays are those that affect cytokine synthesis (glucocorticoids, cyclosporin-CsA, tacrolimus-FK506, Sirolimus-RAPA) and those that affect nucleotide synthesis (azathioprine, Mycophenolate mofetil). ${ }^{1}$

Over the last few years, with the growing use of immunosuppressants, questions have arisen about the action of these medications on bone metabolism ${ }^{9}$. The aim of this literature review is to inform the orthodontist about the influence of immunosuppressants on bony tissue and tooth movement.

\section{LITERATURE REVIEW}

\section{Glucocorticoids (GC)}

Chronic exposure to glucocorticoids constituted the most common cause of secondary osteoporosis, mainly affecting trabecular bone. ${ }^{4}$ Bone loss would be greater in the first 12 to 18 months of therapy and is directly related to the dose and duration of treatment. ${ }^{9}$ Glucocorticoids have great effects on mineral homeostasis, and may stimulate parathyroid hormone (PTH) secretion both in a direct and an indirect manner. ${ }^{9}$ Indirect increase results from diminished intestinal calcium absorption and increase in urinary calcium excretion. In the kidney, there is a reduction in calcium and phosphate tubular absorption. All these mechanisms result in a negative calcium balance, which causes increase in PTH synthesis and secretion, and a consequent increase in bone absorption to maintain the serum calcium level. ${ }^{24}$ It is also known that GCs inhibit the transcription of various cytokine genes, particularly two proteins that bind to DNA to activate IL-2 gene transcription: The cytoplasmic factor (NF-ATc) and the nuclear factor (NF-ATn) of activated T cells. ${ }^{31}$ GCs have shown in vitro capacity to block IL-1, IL-2, IL-3, IL-6, TNFa and IFN-g synthesis, and therefore affect all the stages of the $\mathrm{T}$ cell activation process ${ }^{16}$.

Sobral $^{27}$ observed osteoporosis in the alveolar bone of rabbits 7 days after the application of corticosteroid (Figs 1 and 2); these showed greater tooth movement when compared with normal animals. In 2004, however, Kalia et $\mathrm{al}^{17}$ evaluated the rate of tooth movement in rats, using short and long term therapies, and demonstrated that bone remodeling appeared to diminish with the administration of larger doses in the acute phase, and tooth movement increased when lower doses were administered in chronic treatment. Clinically, these results suggest that it is possible to treat patients submitted to corticoid therapy with minimal side effects. ${ }^{11}$

\section{Cyclosporin (CsA, Sandimmune ${ }^{\circledR}$, Neoral ${ }^{\circledR}$ ); Ta- crolimus (FK-506, Prograf ${ }^{\circledR}$ ) and Sirolimus (RAPA, Rapamycin)}

CsA is a decapeptide (MW=1.200 Daltons) extracted from the fungus Tolypocladium inflatum. Initially described as an inefficient antifungal agent, CsA has been shown to have powerful immunosuppressant activity. ${ }^{5}$ Subsequent immunologic studies have demonstrated that CsA acts on auxiliary and cytotoxic $\mathrm{T}$ lymphocytes (Th and Tc) blocking IL-2 production, the main trophic factor for these cells, as well as other cytokines production, such as IL-1, IL-3 and IFN-g, while the suppressor T lymphocyte (Ts) would be little affected by the drug. ${ }^{1}$ Due to its specific action on lymphokines RNA transcription and synthesis, studies aiming at demonstrating the action mechanisms of CsA have been directed towards understanding the effects of the drug on the regulation of T lymphocyte gene expression.

The binding of CsA to $\mathrm{CyP}$ (cyclophiline, cytoplasmic protein of the family of immunophilines) changes its structural conformation, exposing its hydrophilic sites, binding them to the calcineurines $\mathrm{A}(\mathrm{CnA})$ and $\mathrm{B}(\mathrm{CnB})$, which are serine-threonine phosphatases, 

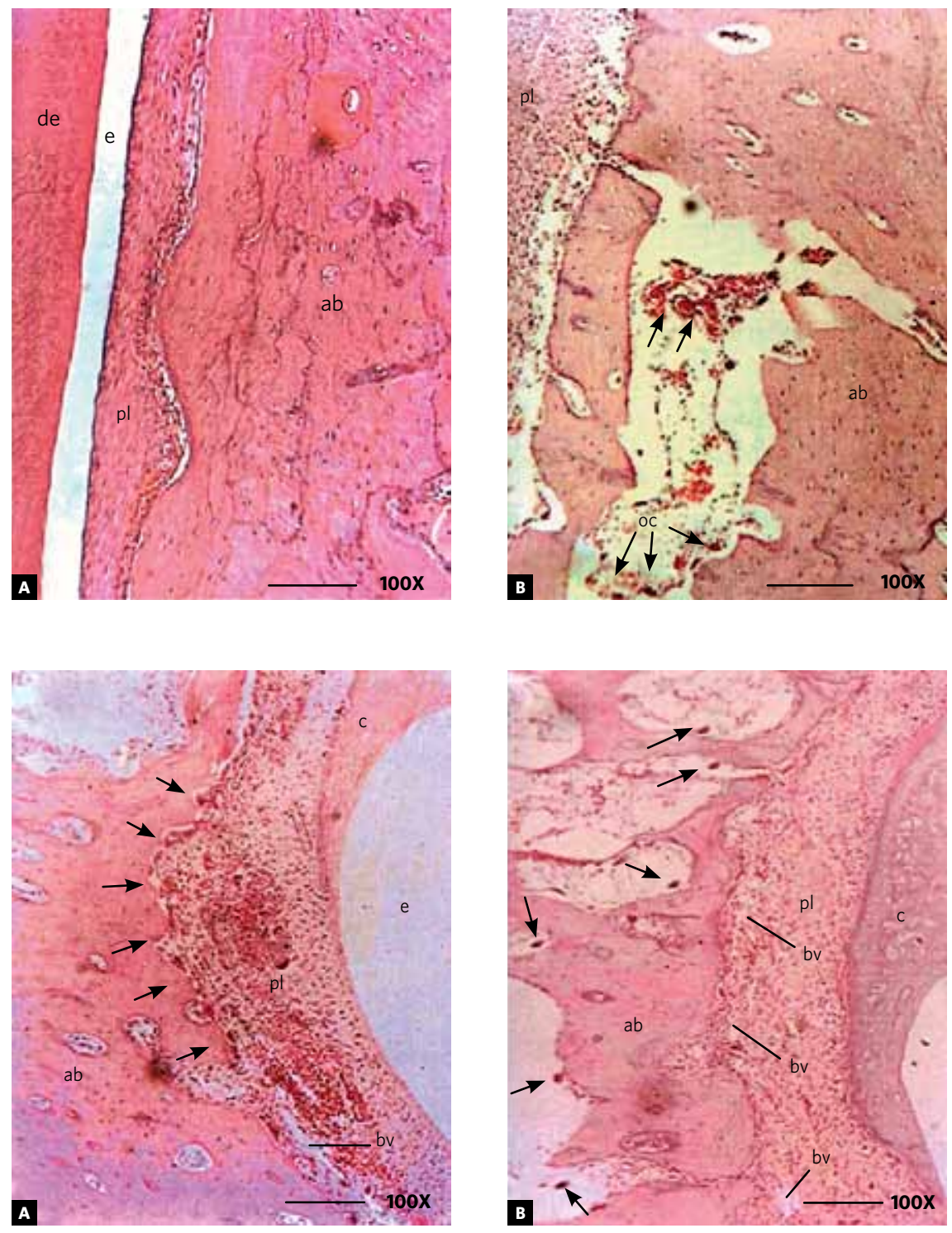

Figure 1 - Photomicrographs of comparative histologic sections between normal bone tissue and tissue with corticosteroid-induced osteoporosis: A) normal bone (control animal) B) osteoporotic bone - cross section from the region between the maxillary $1^{\text {st }}$ and $2^{\text {nd }}$ molars. Dilated blood vessels; ab - alveolar bone; de dentin; e - enamel; pl - periodontal ligament and oc - osteoclasts. Staining - HE. (scale: $100 \mu \mathrm{m})$ (Sobral, 1999).
Figure 2 - Photomicrographs of pressure zones (middle third). A) control animal; B) animal with osteoporosis. ab - alveolar bone; pl - Periodontal Ligament; e - enamel; bv - blood vessels; c - cement; osteoclasts. Staining - HE. (scale: $100 \mu \mathrm{m})$ (Sobral, 1999). associated with calcium ions $(\mathrm{Ca}++)$ and calmoduline $(\mathrm{CaM}){ }^{20}$ The formation of this pentameric complex (CsACyP-CnA-CnB-CaM-Ca) inhibits the enzymatic activity of the phosphatases responsible for the cell activation signals and activation of factors involved in gene transcription regulation that codify the formation of IL-2 and other cytokines. CsA inhibits the NF-AT translocation of activator proteins (AP), regulatory proteins of human gene IL-2, impeding its gene transcription and production. ${ }^{20}$

FK506 is a polycyclic macrolideum (MW=822 Daltons) produced by the fungus Streptomyces tsukubaensis; it is effective and has powerful immunosuppressant activity in vitro and in vivo, even when used in concentrations 100 times lower than those of CsA. ${ }^{12}$ Similarly to CsA, FK506 inhibits the intracellular biochemical pathways dependent on the presence of the calcium ion $(\mathrm{Ca}++)$ and of its interactions with the cytoplasmic receptor, the coupling protein of FK506 (FKBP12), also a rotamase (cis-transprolyl-isomerase) of the family of immunophilines. ${ }^{20}$ Although the immunophilines FKBP and CyP are important for the action of FK506 and CsA, respectively, their actions are limited to concentrating the drugs in the cells and altering their structural conformations. Alone, neither the drugs nor their immunophilines 
are able to bind to or modulate the activities of calcineurine, except in the form of the previously described drug-immunophiline complexes. ${ }^{20}$ FK506 inhibits the early gene of $\mathrm{T}$ cells activation, blocking the expression of the messenger RNA (mRNA) of various inflammatory cytokines (IL-2, IL-3, IL-4 IFN-g). ${ }^{30}$

Recently, Kirino et $\mathrm{al}^{18}$ investigated the effects of tacrolimus on bone metabolism. In this case-control study, the authors administered tacrolimus to test subjects for 6 weeks and verified that after the initial increase in serum osteocalcin concentration, tacrolimus caused its reduction to levels lower than the basal level; the calcemia remained constant throughout the study in spite of the significant increase in calciuria; in the 3rd week, the serum level of PTH was already significantly higher in the test subjects submitted to the immunosuppressant; and when compared with the control group, the test subjects presented thinner bone trabeculae, and wider medullary cavities in some regions, ${ }^{18}$ due to the increase in osteoclastic number and activity. Santo ${ }^{25}$ observed an increase in the number of osteoclasts in alveolar bone of Wistar rats after the administration of FK506 for 4 weeks (Fig 3). On the other hand, studies conducted in cell cultures ${ }^{14}$ demonstrated that messengers RNA of NFATc1, NFATc2, and NFATc3 were present in osteoclastic precursor cells. Recent studies have also shown that FK506 inhibits mainly the final phases of the life cycle of these cells, by the induction of osteoclastic apoptosis. ${ }^{14}$ Taken in conjunction, these findings are in alignment with the notion that the mechanisms by which the agents inhibit osteoclasts and promote osteoclastic apoptosis are similar to those by which the agents inhibit the production of NFAT transcription factor, and the production of inflammatory cytokines in T lymphocytes.

It has been demonstrated that treatment with CsA affects alveolar bone, and that the deleterious periodontal effects may be due to the reduction in bone volume, decrease in number of osteoblasts and increase in osteoclasts. ${ }^{29}$ Despite of the contradictory results, studies have demonstrated that CsA and tacrolimus may induce bone loss both in human beings and in experimental animal models, ${ }^{2}$ through interleukin gene expression (IL-1, IL-6 and tumor necrosis factor - TNF), ${ }^{19}$ cytokines that participate in bone resorption. In vitro, the experimental data obtained from animal models have suggested that tacrolimus is an osteopenic agent, nevertheless, less osteotoxic than CsA. ${ }^{13}$

In fact, the results obtained from therapy with CsA-induced in which was observed a marked gingival growth and bone loss in rats, ${ }^{28}$ are much more uniform than those observed in man. ${ }^{13}$
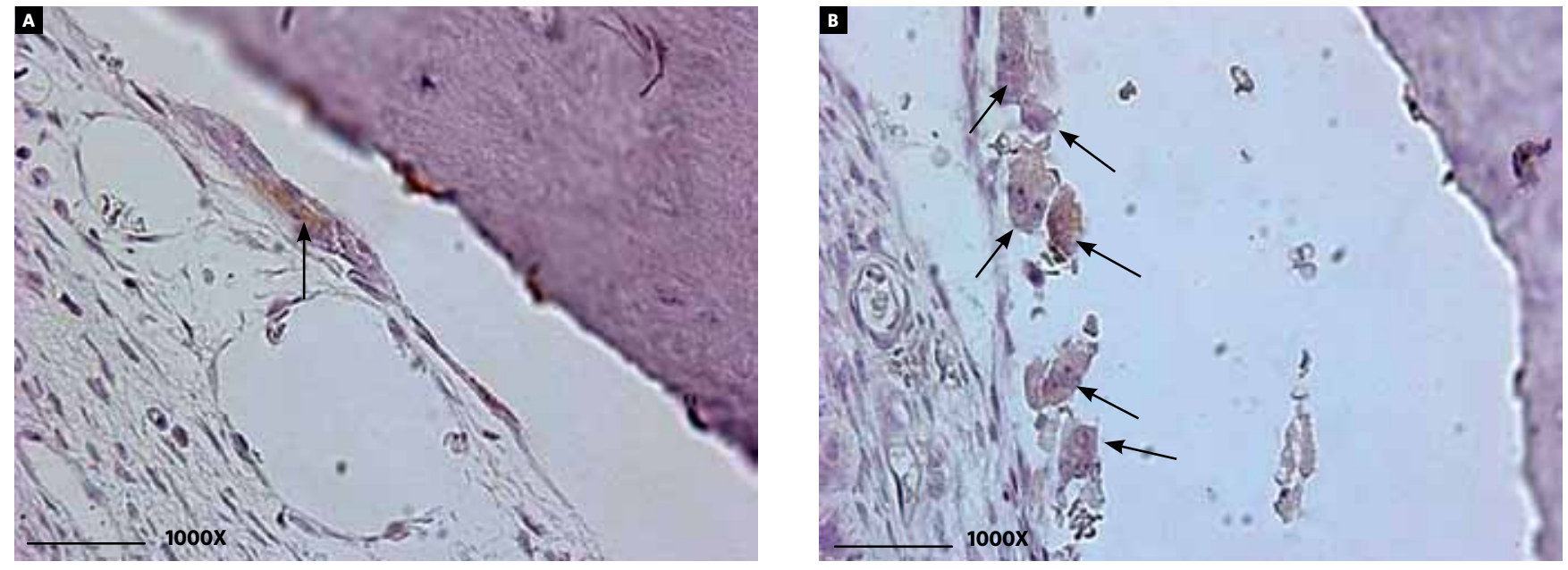

Figure 3 - Photomicrographs of histologic sections in immunohistochemistry $\left(E D 1^{+}\right)$in cross section of the region situated between the maxillary incisors for osteoclasts (multinucleated giant cells, located within the alveolar bone or at the bone surface) (arrow) on the control animal's pressure side, without treatment with

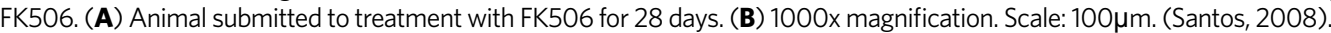


With a very similar structure to that of FK506, ${ }^{1}$ RAPA is a macrolide (MW=914 Daltons) produced by the fungus Streptomyces hygroscopicus. Differently from CsA and FK506, RAPA does not affect cytokine synthesis, but impedes the response to these hormones by blocking the transduction signal generated by cytokine receptors, impeding the progression of the cell cycle in phase Gl. The RAPA immunosuppression mechanism has been better explained with the knowledge about two important domains in its molecular structure: One domain of bonding to immunophiline FKBP12 and the other to mTOR protein. RAPA blocks $\mathrm{T}$ cell protein synthesis, probably by inhibition of 70-KD56 kinases (p7056K). ${ }^{8}$

Some authors have suggested that RAPA has strong anti-angiogenic activity linked to reduction of vascular endothelial growth factor (VEGF), and causes less proliferation of osteoblasts, endothelial cells and periosteal cells; thus, inhibiting cell proliferation and neovascularization. ${ }^{15}$

The use of this immunosuppressant for long periods $^{6}$ or in high doses increases bone remodeling and inhibits longitudinal bone growth, reducing growth speed by approximately 30 to $50 \%,{ }^{3}$ in addition to inhibiting different cell types, including smooth muscle vascular cells and fibroblasts, which do not compose of the immune system. ${ }^{32}$

\section{OTHER IMMUNOSUPPRESSANTS}

\section{Mycophenolate mofetil (MPA, Micophenolic Acid, MMF, Cellcept ${ }^{\circledR}$ ) and Azathioprine (AZA)}

RS-61443 is the semi-synthetic morpholinoethyl ester pro-drug, also known as Mycophenolate mofetil which, when activated by hydrolysis is transformed into micophenolic acid (MPA). ${ }^{22}$ After oral administration and absorption, RS-61443 is converted into MPA which is later metabolized in the liver into its inactive form. Regeneration of the active form (MPA) is done by beta-glucuronidase enzymes, which apparently are in elevated concentrations in activated $\mathrm{T}$ and $\mathrm{B}$ cells and macrophages which, perhaps for this reason, these cells are very sensitive to the action of the drug ${ }^{23}$. Mycophenolate mofetil used in immunosuppressant therapy showed no deleterious effect on bone mineral density. ${ }^{10}$

Azathioprine is an immunosuppressant used with some frequency in post-transplant therapy, together with glucocorticoids and calcineurine-phosphatase inhibitors. Bryer et $\mathrm{al}^{6}$ have shown that azathioprine does not modify bone mass.

Considering that bone disease is so common on organ transplant candidates, all these patients should be evaluated with regard to the presence of osteoporosis and mineral metabolism disorders. After the transplant, they should be subjected to bone loss prevention therapy, and although there is no consensus, anti-resorptive treatment with bisphosphonates would appear to be the best option. ${ }^{9}$

\section{ANTI-RESORPTIVE MEDICATION Bisphosphonates}

Laboratory studies have demonstrated that tooth movement may be inhibited by the topical application of biphosphonates. ${ }^{21}$ In 2004, Liu et $\mathrm{al}^{21}$ applied bisphosphonate in the subperiosteal molar region in rats subjected to orthodontic forces for three weeks. At the application site there was a reduction in quantity of orthodontic movement, number of osteoclasts and root resorption. Further studies will be necessary before these drugs may be used in Orthodontics. ${ }^{11}$ In 2005, Schwartz ${ }^{26}$ described an important case of a patient under orthodontic treatment, who was being medicated with Zometa (Novartis, East Hanover, NJ, USA) to control bone metastases related to breast cancer. The premolar extraction space had been orthodontically closed by one third; at the time when this patient began treatment with this medication tooth movement was interrupted. ${ }^{26}$

\section{DISCUSSION}

The use of immunosuppressants by transplanted patients and those with auto-immune diseases are partly responsible for their longer survival, however, the use of immunosuppressants may influence bone metabolism $^{9}$ and consequently, tooth movement in patients undergoing orthodontic treatment, who use these medications.

Bone metabolism is significantly altered by chronic exposure to glucocorticoids, this being the most common cause of secondary osteoporosis, mainly affecting trabecular bone. ${ }^{4}$ Bone loss is generally greater in the first 12 to 18 months of therapy and is directly related to the dose and duration of treatment, ${ }^{9}$ as observed by Sobral ${ }^{27}$ and Kalia et al $^{17}$ 
who showed greater tooth movement in animals subjected to these medications. As occurs with glucocorticoids, Cyclosporine affects alveolar bone causing deleterious periodontal effects that may be due to the reduction in bone volume and number of osteoblasts, and increase in osteoclasts. ${ }^{29}$ In rats marked gingival growth and bone loss were observed ${ }^{28}$, however more uniformly than those observed in human beings ${ }^{13}$ due to environmental and genetic factors.

Recently, Kirino et $\mathrm{al}^{18}$ in a study with animals submitted to the application of tacrolimus, observed thinner bone trabeculae, wider medullary cavities ${ }^{18}$ and increase in the number of osteoclasts. ${ }^{25}$ Studies have demonstrated that both Cyclosporin and tacrolimus may induce bone loss both in human beings and in experimental animal models, ${ }^{2}$ through interleukin gene expression (IL-1, IL-6 and tumor necrosis factor-TNFa), ${ }^{19}$ the cytokines that participate in bone resorption.

Immunosuppressant activity with Rapamicine for long periods ${ }^{6}$ or in high doses increases bone remodeling and inhibits longitudinal bone growth, reducing the speed of growth by around 30 to $50 \%,{ }^{3}$ in addition to inhibiting different cell types, including smooth muscle vascular cells and fibroblasts that are not part of the immune system..$^{32}$ Other immunosuppressants such as, Mycophenolate mofetil ${ }^{10}$ and Azathioprine ${ }^{6}$ showed no deleterious effects on bone mineral density.

Immunosuppressants represent great advancement in the control of different types of diseases, and suppression of the immune response against transplanted organs, however, a large portion of these medications are capable of influencing bone metabolism and tooth movement.

The orthodontist may frequently encounter patients that require prolonged immunosuppressive therapy and orthodontic treatment. Usually, patients in the initial stage of these medications usage may be advised to delay orthodontic treatment, as there would be less bone remodeling, or orthodontic activation appointments should be scheduled at longer intervals. On the other hand, long term medication therapy may accelerate tooth movement, thus orthodontic appliances must be adjusted customarily, or with greater frequency. Medical follow-up with clinical and densitometry periodic exams are necessary in order to obtain more predictable and satisfactory orthodontic results.

\section{CONCLUSION}

1) Immunosuppressants that affect cytokine synthesis (glucocorticoids, cyclosporin-CsA, tacrolimus-FK506 and Sirolimus-RAPA) interfere in bone metabolism and may influence tooth movement.

2) Interference in bone metabolism is dependent on the force applied, dose and duration of immunosuppressant therapy, in addition to the individual response of each patient, except to azathioprine and Mycophenolate mofetil that have shown no deleterious effect on bone density. 


\section{REFERENCES}

1. Abbud-Filho M, Ramalho HJ. Revisão/atualização em transplante renal: novos agentes imunossupressores. J Bras Nefrol. 1997;19(2):215-23.

2. Abdelhadi M, Ericzon BG, Hultenby K, Sjöden G, Reinholt FP, Nordenström J. Structural skeletal impairment induced by immunosuppressive therapy in rats: cyclosporine A vs tacrolimus. Transpl Int. 2002;15(4):180-7. Epub 2002 Apr 6.

3. Alvarez-Garcia O, Carbajo-Pérez E, Garcia E, Gil H, Molinos I, Rodriguez J, et al. Rapamycin retards growth and causes marked alterations in the growth plate of young rats. Pediatr Nephrol. 2007;22(7):954-61. Epub 2007 Mar 17.

4. Boling EP. Secondary osteoporosis: underlying disease and the risk for glucocorticoid-induced osteoporosis. Clin Ther. 2004;26(1):1-14.

5. Borel JF, Feurer C, Gubler HU, Stähelin H. Biological effects of cyclosporin A: a new antilymphocytic agent. Agents Actions. 1976;6(4):468-75.

6. Bryer HP, Isserow JA, Armstrong EC, Mann GN, Rucinski B, Buchinsky FJ, et al. Azathioprine alone is bone sparing and does not alter cyclosporin A-induced osteopenia in the rat. J Bone Miner Res. 1995;10(1):132-8.

7. Canalis E, Giustina A. Glucocorticoid-induced osteoporosis: summary of a workshop. J Clin Endocrinol Metab. 2001;9(86):5681-5.

8. Chung J, Kuo CJ, Crabtree GR, Blenis J. Rapamycin-FKBP specifically blocks growth-dependent activation of and signaling by the $70 \mathrm{kd} \mathrm{S6}$ protein kinases. Cell. 1992;69(7):1227-36.

9. Cipriani RE, Farias ML. Osteoporose após transplante de órgãos sólidos. Arq Bras Endocrinol Metabol. 2005;49(3):369-77.

10. Dissanayake IR, Goodman GR, Bowman AR, Ma Y, Pun S, Jee WS, et al. Mycophenolate mofetil: a promising new immunosuppressant that does not cause bone loss in the rat. Transplantation. 1998;65(2):275-8.

11. Gameiro GH, Pereira-Neto JS, Magnani MB, Nouer DF. The influence of drugs and systemic factors on orthodontic tooth movement. J Clin Orthod. 2007;41(2):73-8; quiz 71.

12. Goto $T$, Kino $T$, Hatanaka $H$, Nishiyama $M$, Okuhara $M$, Kohsaka $M$, et al. Discovery of FK-506, a novel immunosuppressant isolated from Streptomyces tsukubaensis. Transplant Proc. 1987;19(5 Suppl 6):4-8

13. Guimarães MR, Nassar PO, Andia DC, Nassar CA, Spolidorio DM, Rossa C Jr, et al. Protective effects of Tacrolimus, a calcineurin inhibitor, in experimental periodontitis in rats. Arch Oral Biol. 2007;52(9):882-8. Epub 2007 Mar 23.

14. Hirotani $\mathrm{H}$, Tuohy NA, Woo JT, Stern PH, Clipstone NA. The calcineurin/nuclear factor of activated $\mathrm{T}$ cells signaling pathway regulates osteoclastogenesis in RAW264.7 cells. J Biol Chem. 2004;279(14):13984-92.

15. Holstein JH, Klein M, Garcia P, Histing T, Culemann U, Pizanis A, et al. Rapamycin affects early fracture healing in mice. Br J Pharmacol. 2008;12(14):210-21.

16. Hricik DE, Almawi WY, Strom TB. Trends in the use of glucocorticoids in renal transplantation. Transplantation. 1994;57(7):979-89.

17. Kalia S, Melsen B, Verna C. Tissue reaction to orthodontic tooth movement in acute and chronic corticosteroid treatment. Orthod Craniofac Res. 2004;7(1):26-34
18. Kirino S, Fukunaga J, Ikegami S, Tsuboi H, Kimata M, Nakata N, et al. Regulation of bone metabolism in immunosuppressant (FK506)-treated rats. J Bone Miner. Metab. 2004 Jun;22(6):554-60.

19. Lee WY, Baek KH, Rhee EJ, Tae HJ, Oh KW, Kang MI, et al. Impact of circulating bone-resorbing cytokines on the subsequent bone loss following bone marrow transplantation. Bone Marrow Transplant. 2004;34(1):89-94.

20. Liu J, Farmer JD Jr, Lane WS, Friedman J, Weissman I, Schreiber SL. Calcineurin is a common target of cyclophilin-cyclosporin A and FKBP-FK506 complexes. Cell. 1991;66(4):807-15.

21. Liu L, Igarashi K, Haruyama N, Saeki S, Shinoda H, Mitani H. Effects of local administration of clodronate on orthodontic tooth movement and root resorption in rats. Eur J Orthod. 2004;26(5):469-73.

22. Makowka L, Chapman F, Cramer DV. Historical development of brequinar sodium as a new immunosuppressive drug for transplantation. Transplant Proc. 1993;25(3 Suppl 2):2-7.

23. Morris RE. Immunopharmacology of new xenobiotic immunosuppressive molecules. Semin Nephrol. 1992;12(4):304-14.

24. Negri AL, Plantalech LC, Russo Picasso MF, Otero A, Sarli M. Post-transplantation osteoporosis. Medicina. 1999;59(6):777-86.

25. Santos RL. Ação do tacrolimus no ligamento periodontal e osso alveolar em ratos Wistar durante a movimentação ortodôntica [dissertação]. Rio de Janeiro (RJ): Universidade Federal do Rio de Janeiro; 2008.

26. Schwartz JE. Ask us: Some drugs affect tooth movement. Am J Orthod Dentofacial Orthop. 2005;127(6):644.

27. Sobral MC. Avaliação do movimento dentário em coelhos com osteoporose induzida por corticosteróides [dissertação]. Rio de Janeiro (RJ): Universidade Federal do Rio de Janeiro; 1999

28. Spolidorio LC, Holzhausen M, Spolidorio DM, Nassar CA, Nassar PO, Muscará MN Cyclosporin but not tacrolimus significantly increases salivary cytokine contents in rats. J Periodontol. 2005;76(9):1520-5.

29. Spolidorio LC, Marcantonio E Jr, Spolidorio DM, Nassar CA, Nassar PO, Marcantonio RA, et al. Alendronate therapy in cyclosporine-induced alveolar bone loss in rats. J Periodontal Res. 2007;42(5):466-73.

30. Thomson AW, Bonham CA, Zeevi A. Mode of action of tacrolimus (FK506): molecular and cellular mechanisms. Ther Drug Monit. 1995;17(6):584-91.

31. Vacca A, Felli MP, Farina AR, Martinotti S, Maroder M, Screpanti I. Glucocorticoid receptor-mediated suppression of the interleukin 2 gene expression through impairment of the cooperativity between nuclear factor of activated T cells and AP-1 enhancer elements. J Exp Med. 1992;175(3):637-46

32. Waller JR, Brook NR, Bicknell GR, Murphy GJ, Nicholson ML. Mycophenolate mofetil inhibits intimal hyperplasia and attenuates the expression of genes favouring smooth muscle cell proliferation and migration. Transplant Proc. 2005;37(1):164-6. 